\title{
Grid-Connected Forward Microinverter With Primary-Parallel Secondary-Series Transformer
}

\author{
David Meneses, Oscar García, Pedro Alou, Jesús A. Oliver and José A. Cobos
}

\begin{abstract}
This paper presents a primary-parallel secondaryseries multicore forward microinverter for photovoltaic ac-module application. The presented microinverter operates with a constant off-time boundary mode control, providing MPPT capability and unity power factor. The proposed multitransformer solution allows using low-profile unitary turns ratio transformers. Therefore, the transformers are better coupled and the overall performance of the microinverter is improved. Due to the multiphase solution, the number of devices increases but the current stress and losses per device are reduced contributing to an easier thermal management. Furthermore, the decoupling capacitor is split among the phases, contributing to a low-profile solution without electrolytic capacitors suitable to be mounted in the frame of a PV module. The proposed solution is compared to the classical parallel-interleaved approach, showing better efficiency in a wide power range and improving the weighted efficiency.
\end{abstract}

Index Terms-AC-module, microinverter, multiphase, photovoltaic.

\section{INTRODUCTION}

$\mathbf{T}$ RADITIONALLY, central inverter technology is used to overcome the low voltage generated by photovoltaic (PV) arrays. However, in residential applications, the energy yield is jeopardized due to mismatches and partial-shading. Distributed maximum power point tracking (DMPPT) architectures, in both dc-dc and dc-ac systems, improve the energy harvesting capability by means of a module-integrated converter [1], [2]. Despite nonisolated solutions have been presented for both dcdc optimizers [3] and ac-module applications [4], the use of a transformer is widespread providing flexibility, an adequate voltage boost and compliance with safety standards [5]-[10].

Current-fed-isolated converters are widely used in DMPPT architectures [6]-[8] due to their inherent boosting capabilities. Single-stage flyback inverter is a commonly used topology in acmodule applications due to its simple structure [9], [10]. Buckderived topologies are mainly used as step-up dc-dc converters in two-stage inverters [11], [12]. In these topologies, the required turns ratio to achieve an appropriate voltage boosting is large.

A large turns ratio complicates the achievement of good coupling between primary and secondary, thus resulting in high leakage inductance and extra losses in the windings [11]. Splitting the transformer in unitary turns ratio transformers is proposed in [11] to improve the converter performance, while the thermal management is better and transformer manufacturing cost is reduced because of the mass production possibility. Furthermore, the possibility of splitting the converter in several smaller converters with unity ratio transformer is suggested.

The use of parallel-interleaved converters is common in lowvoltage high-current applications to reduce the current stress and magnetic components size. In addition, light load efficiency is improved by connecting or disconnecting phases [10], [13], [14]. In [5], an isolated boost converter with parallel-interleaved primary and series-connected secondary is presented, thus reducing current stress in the primary side and improving voltage gain. Similar configurations are also presented in [15] and [16] using planar magnetics. The interleaved operation of forward converters is well known [17] and the secondary side series connection has also been presented with different configurations [18], [19] for dc-dc applications.

This paper presents a primary-parallel secondary-series forward inverter for ac-module application. In Section II, the single-transformer approach is presented, analyzing the operation mode to achieve unitary power factor. Section III introduces the multitransformer topology as well as the operation principle and the main design considerations. The light load operation of the inverter is analyzed in Section IV and the estimated weighted efficiency for the analyzed configurations is compared. In Section V, the transformers design and size are compared for configurations with different number of transformers. Finally, Section VI shows experimental results for the single-transformer and the two- and eight-transformer microinverters and a comparison with the experimental results of the interleaved forward microinverter.

\section{Single-STAGe BOUNDARY Mode-CONTROLLED FORWARD MICROINVERTER}

Single-phase grid-connected PV inverters present similarities with the power factor correction (PFC) application and control [20], power decoupling [21] strategies as well as topologies [22] from PFC have been adapted to PV inverters.

A buck converter connected between the solar panel and the grid using an unfolder stage, thus working as a current source, is shown in Fig. 1. As in the boost converter in PFC applications, if the buck converter is operated in the boundary (BCM) between continuous (CCM) and discontinuous conduction mode (DCM) the injected current to the grid is proportional to the grid voltage (see Fig. 2). By analyzing the average current value in 


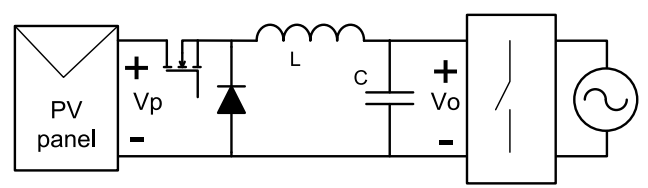

Fig. 1. Buck converter connected between a PV panel and the grid.

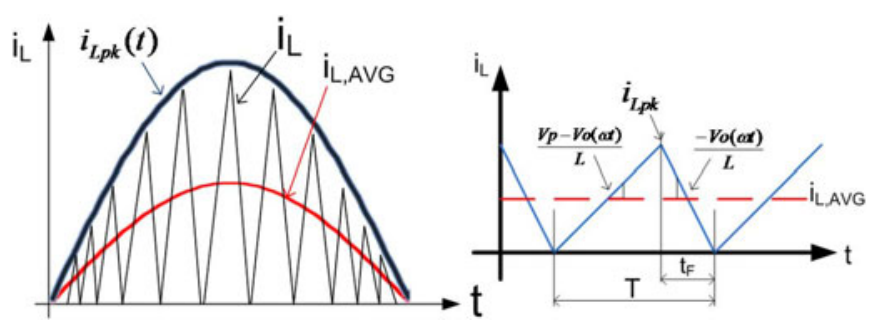

Fig. 2. Buck inductor current within a grid half-period and within a switching period.

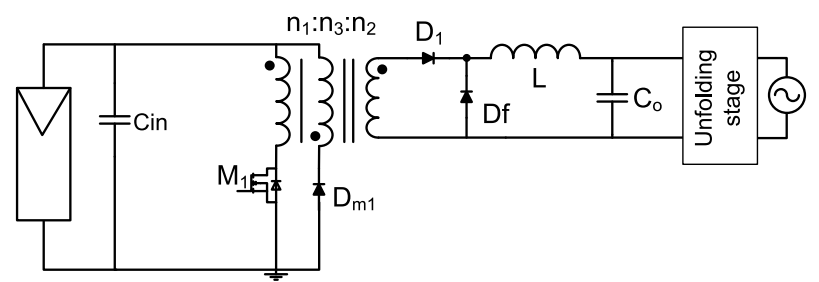

(a)

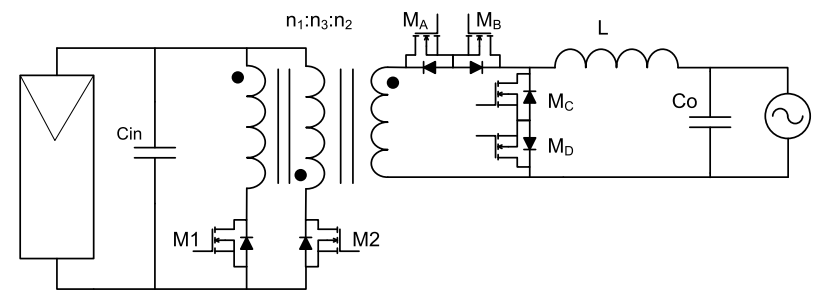

(b)

Fig. 3. (a) Proposed single-stage forward micro-inverter with unfolder stage and (b) with bidirectional secondary side switches.

a switching cycle, it can be concluded that this is possible if the off-time is kept constant (1)

$$
\begin{aligned}
i_{L, \mathrm{AVG}} & =\frac{1}{2} \cdot i_{L p k}=\frac{1}{2} \cdot \frac{V o(\omega t)}{L} \cdot t_{F} \\
& =K \cdot V o(\omega t), \text { if } t_{F}=\text { const. }
\end{aligned}
$$

In the case of ac-module application, the input voltage is up to 50 or $100 \mathrm{~V}$ for crystalline silicon and thin-film modules, respectively [4]. As a consequence, a boosting transformer is necessary for grid interface, especially for the European grid voltage. Several isolated buck-derived topologies can be used. However, due to the low power range of the commercial PV modules, simple topologies as forward converter are preferred.

Two possible implementations are proposed for the singlestage forward microinverter, as shown in Fig. 3: a) with unfolding stage and $b$ ) with secondary side switches.

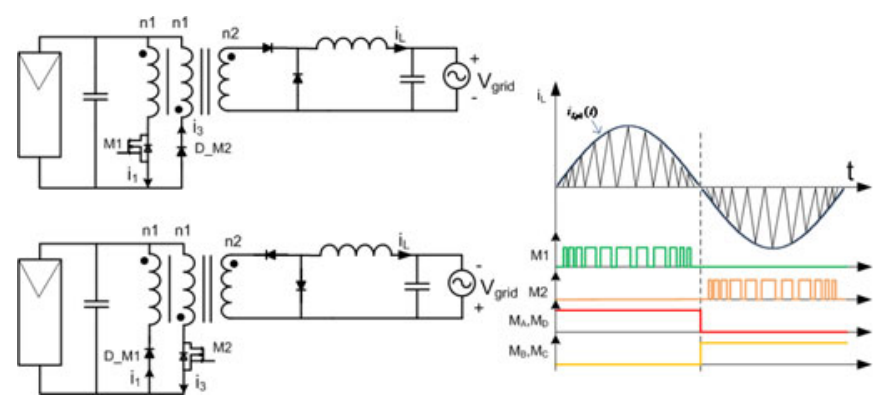

Fig. 4. Equivalent circuits for positive and negative grid voltage operation.

In both cases, the primary transistors are high-frequency switched to operate the microinverter in the boundary mode. Implementation b) integrates the unfolding stage in the microinverter power stage, i.e., the secondary side bidirectional switches are line frequency switched according to the grid voltage polarity. Thus, two subcircuits are generated as depicted in Fig. 4. Therefore, the two primary windings are used either for energy transfer or transformer reset during the corresponding grid half-cycle and the primary to tertiary turns ratio is forced to be the same. Furthermore, both primary windings are designed for the same current stress; hence, a bigger core is needed.

\section{Primary-Parallel Secondary-Series Multicore TRANSFORMER FORWARD MICROINVERTER}

In the configurations presented in Fig. 3, the necessary primary to secondary turns ratio to achieve a proper interfacing between the low PV module voltage and the grid is large, thus the performance of the converter can be worsened. Fig. 5 shows the proposed multicore forward topology derived from the topology presented in Fig. 3(a), which consists of several highly coupled transformers which are parallel connected in the primary side and series connected in the secondary side.

The parallelization in the primary side reduces the current stress in both switches and primary windings of the transformer. The current sharing is guaranteed because of the secondary series connection, although affected by the coupling of the individual transformers. The current stress is also decreased in the secondary side diodes due to the common cathode configuration and the synchronized driving of the primary switches. As a result, SMD devices can be used, a low-profile implementation is feasible and the thermal management is improved, although more devices are needed.

The secondary series connection allows achieving the grid voltage using transformers of lower turns ratio. Therefore, the primary to secondary coupling at each transformer can be significantly improved, i.e., primary side current sharing is improved and parameters such as leakage inductance can be reduced, thus improving the off transition of the primary transistors.

\section{A. Operation Principle, Voltage Gain and Transformers Turns Ratio}

The primary switches are synchronized and sinusoidally modulated following the boundary mode control (BCM) strategy to 


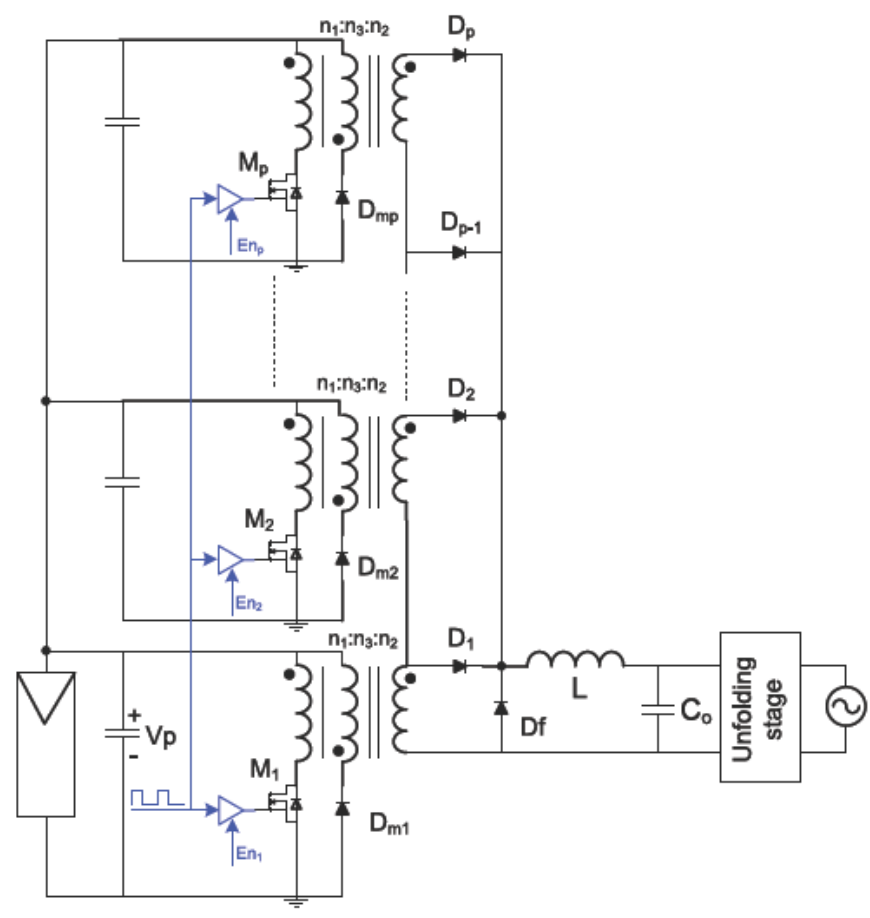

Fig. 5. Proposed forward microinverter topology with primary-parallel secondary-series-connected transformers.

generate a rectified sinusoidal current, which is unfolded in a line frequency switched bridge to inject unitary power factor current to the grid. Therefore, the application of the presented topology is intended for those grid connections where grid support is not demanded by the grid operator [23]. Furthermore, in order to comply with the harmonic requirements of the different standards [4], an EMI filter is necessary after the unfolding stage [24].

The high-frequency operation of the topology can be divided in two intervals as the classical forward converter operating in $\mathrm{BCM}$. The main ideal waveforms of the proposed solution when two phases are active for a four-transformer inverter are shown in Fig. 6. As it can be observed, the common cathode configuration of the secondary diodes together with the synchronized control strategy make that only one of the secondary side diodes is in the current path at each moment. The number of active phases at each moment is decided according to the grid voltage as shown in Fig. 7 for the four-transformer inverter.

As shown in the presented ideal waveforms, during the on time the voltage applied to the output filter is proportional to the number of active phases. During off-time, the inductor current flows through the free-wheeling diode in the same manner than in classical forward converter. Therefore, the voltage gain can be expressed as

$$
V o=n \cdot m \cdot d \cdot V p
$$

where " $m$ " is the number of active phases (e.g., $\mathrm{m}=2$ in Fig. 6), " $V p$ " the PV panel voltage, " $d$ " the applied duty cycle and " $n$ " is the primary to secondary turns ratio $\left(n_{2} / n_{1}\right)$ of each transformer, which is considered to be the same.

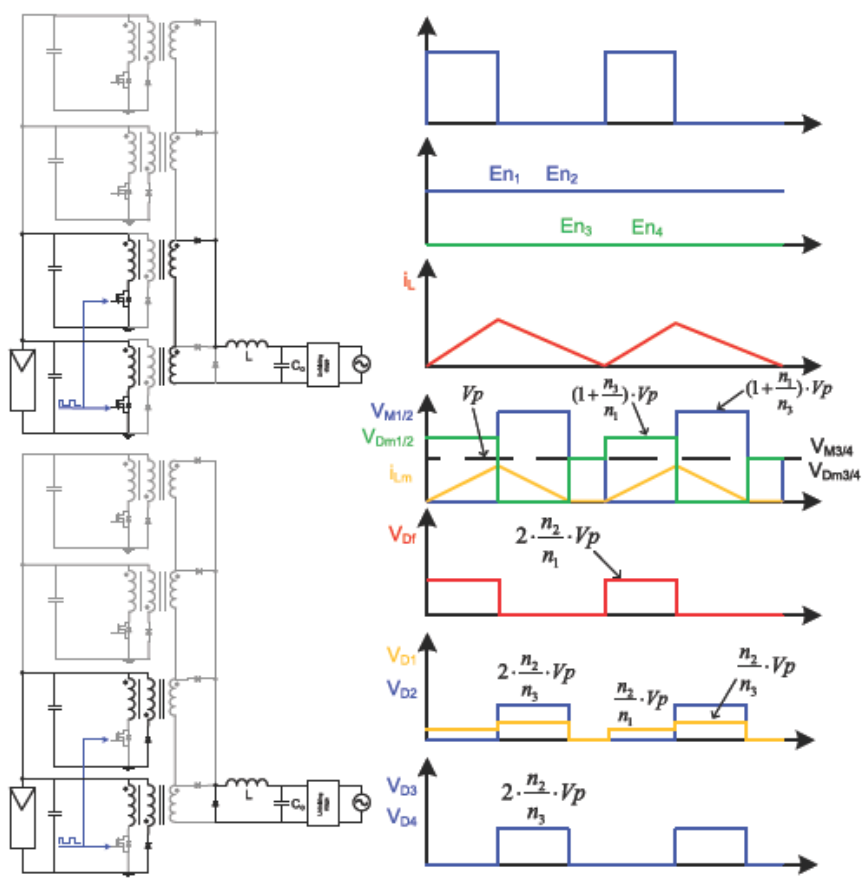

Fig. 6. Ton and Toff configurations (left) and main waveforms (right) of the proposed converter when two phases are active.

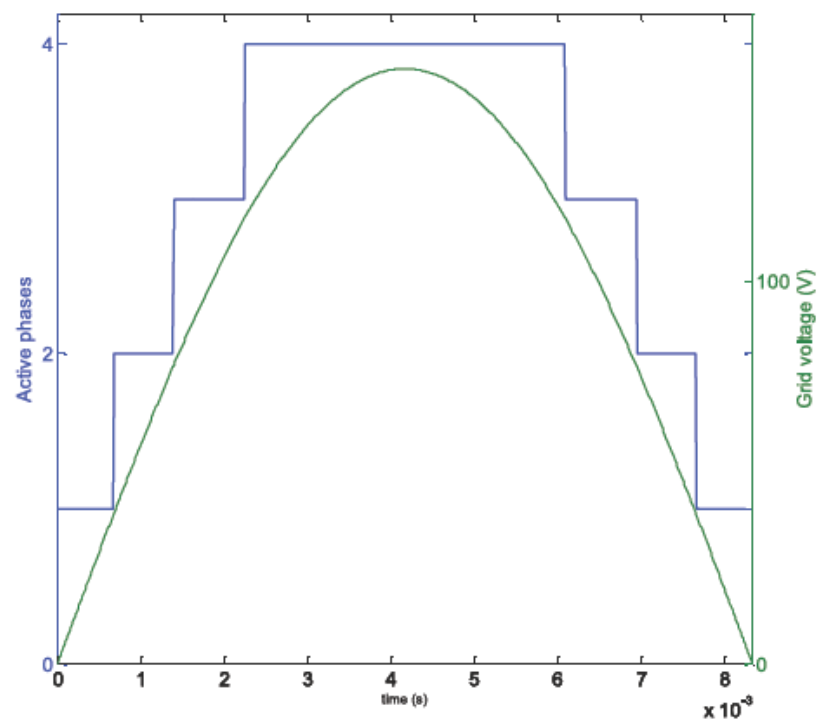

Fig. 7. Number of active phases during a line period for a four-transformer forward microinverter.

Using the presented voltage gain, the primary to secondary turns ratio of an individual transformer can be calculated as a function of the total number of transformers used " $p$ " (e.g., $p=4$ in Fig. 6), for a given solar module and a grid voltage (3)

$$
n=\frac{n 2}{n 1}=\frac{V o_{\text {peak }}}{p \cdot d_{\max } \cdot V p_{\min }} .
$$




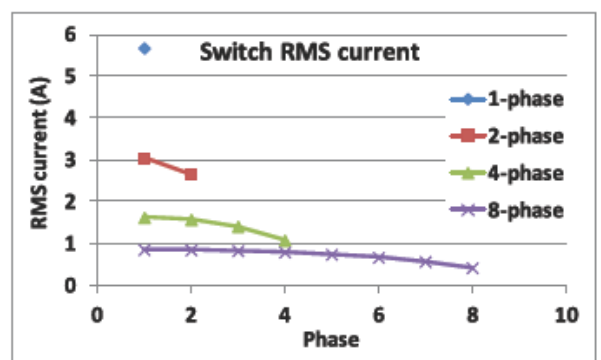

(a)

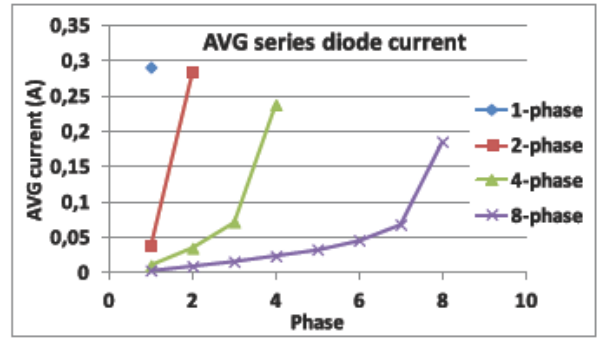

(b)

Fig. 8. (a) Primary switches rms current and (b) secondary series diodes AVG current during a grid period.

\section{B. Inductor Value and Variable Frequency Operation}

The applied BCM strategy ensures the injection of unity power factor current to the grid. However, the converter is operated with variable frequency and a trade-off between the chosen maximum frequency and the necessary inductance value (rms currents inside the circuit) must be achieved, for a given power level (4). With regard to the minimum operation frequency of the converter, it can be calculated as in (5), where " $p$ " is the total number of phases

$$
\begin{aligned}
f_{\max } & =\frac{V_{O \_ \text {RMS }}^{2}}{2 \cdot L \cdot P o} \\
f_{\min } & =\left(1-\frac{V_{O_{-} p k}}{n \cdot p \cdot V p}\right) \cdot f_{\max } .
\end{aligned}
$$

\section{Component Stress}

Since the operation of the proposed converter is the same than in a classical forward converter, the primary side component voltage stress in the proposed solution is also the same. However, the parallel operation of the converter reduces the current stress due to the current sharing, even more in the phases which are not active during the whole line period [see Fig. 8(a)].

With regard to the secondary side, only one of the series diodes $\left(D_{\mathrm{i}}\right.$ in Fig. 5$)$ is in the current path at each moment due to the applied series configuration so the current stress is reduced in the secondary side diodes [see Fig. 8(b)]. The current stress of the free-wheeling diode remains the same regardless the number of transformers used.

The current stress reduction in both primary and secondary side components allows the utilization of SMD components, which provides advantages for the ac-module application such as thermal management or low-profile implementation. How- ever, the increase in the number of components increases considerably the cost of the solution when the number of transformers is large. A qualitative cost comparison for the eight-transformer configuration respect to the single-transformer one is presented in the experimental results section.

The voltage stress for the freewheeling diode and the "ith" series diode of the secondary side can be calculated according to (6) and (7), where " $p$ " is the total number of transformers for the selected configuration

$$
\begin{aligned}
V_{\mathrm{KA} \_\mathrm{FW}} & =p \cdot \frac{n_{2}}{n_{1}} \cdot V p \\
V_{\mathrm{KA} \_D i} & =\max \left[(p-i) \cdot \frac{n_{2}}{n_{1}} \cdot V p, i \cdot \frac{n_{2}}{n_{3}} \cdot V p\right] .
\end{aligned}
$$

\section{Semiconductor Losses Estimation}

In the case of the primary switches, both the rms value and the voltage-current product when the switch is turned OFF are calculated at each switching cycle. Afterwards, those calculated values are used to compute the average in a line period. The same procedure is used for the mean values of the diode currents. The semiconductor losses can be calculated according to (8) and (9)

$$
\begin{aligned}
& P_{\mathrm{Switch} \_}=1.6 \cdot R_{\mathrm{DSon}} \cdot\left(\frac{1}{k} \cdot \sum_{k, T_{\mathrm{grid}}} I_{M i \_ \text {RMS_ } \_}\right)^{2} \\
& +\frac{1}{2} \cdot\left(\sum_{k, T_{\text {grid }}} V_{\mathrm{OFF}_{-} i} \cdot I_{M i_{-} p k}\right) \cdot t_{\text {fall }} \cdot f_{\text {grid }} \\
& P_{\text {Diode }_{\_} j}=V_{F_{-} j} \cdot \frac{1}{k} \cdot \sum_{k, T_{\text {grid }}} I_{D j \_ \text {avg } \_k} .
\end{aligned}
$$

\section{E. Input Capacitor (Line Frequency Power Decoupling)}

In the proposed topology, the primary switches are synchronized and therefore there is no possibility to reduce the necessary input capacitance to filter the high-frequency ripple of the input current, as in interleaved converters. However, in the case of single-stage microinverters, like the proposed in this paper, the input capacitance is designed to guarantee a proper balance between the demanded twice-line frequency current and the dc current provided by the PV module [21]. A proper power balance allows low voltage ripple in the PV module in order to ensure a high maximum power point tracking (MPPT) efficiency. Due to the low voltage in the PV module, a large capacitance is required in parallel with the PV module (2 mF@ $45 \mathrm{~V} / 120 \mathrm{~W}$, for 8.5\% of voltage ripple [25]), which is typically some orders of magnitude larger than the required capacitance for high-frequency filtering. As a consequence, in most of the cases an electrolytic capacitor is used, which is bulky and may reduce the life span of the solutions.

In the proposed topology, this capacitance is distributed among the paralleled primaries, thus reducing the capacitor of each phase. Therefore, low profile ceramic capacitors can be used, making the proposed configuration suitable for ac-module application. 

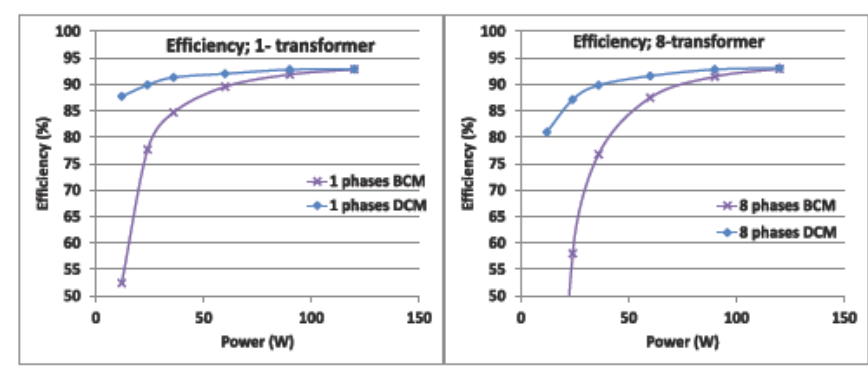

Fig. 9. Calculated efficiency for different configurations at DCM and BCM operation.

\section{EFFICIENCY AND LIGHT-LOAD DCM OPERATION}

In PV applications, the power operation range is wide due to the dependence on the changeable irradiance and temperature conditions. Due to the selected control strategy, the operating frequency range of the proposed solution increases when the delivered power from the PV module decreases, according to (4) and (5). As a consequence, the inverter efficiency at light load operation is jeopardized because of the increase in the switching losses. As depicted in Fig. 9, this effect is penalized when the number of transformer increases due to the higher number of utilized switches. Therefore, DCM operation is used in order to improve the efficiency at light load operation.

In DCM operation, it is necessary a control law to keep the unitary power factor as in the proposed boundary mode control strategy. This control law, presented in (10), can be derived by making the inductor current average value proportional to the grid voltage. It must be noticed that the turns ratio " $n$ " has to be updated when the number of used phases changes

$$
\begin{aligned}
d(t) & =M(t) \cdot \sqrt{\frac{k_{\mathrm{DCM}}}{n \cdot(n-M(t))}} ; k_{\mathrm{DCM}} \\
& =\frac{2 \cdot L \cdot f_{\mathrm{sw}}}{V_{o_{-} \mathrm{RMS}}^{2}} \cdot P_{o} ; M(t)=\frac{v_{o}(t)}{V p} .
\end{aligned}
$$

Fig. 10 shows how the estimated efficiency changes with the PV module power as well as the conduction mode of operation and the calculated CEC efficiency [28] for the considered configurations. According to the calculated efficiency for the analyzed designs, such as the presented in Fig. 9, the operation mode is changed when the available power is lower than $80 \%$ of the considered maximum power.

As it can be seen, the estimated weighted efficiency is similar for the analyzed configurations. However, the calculation excludes the effect of leakage inductance which is expected to be significant for the single transformer configuration, since the turns ratio is far from unity.

\section{TRANSFORMER Size AND LoSSES ESTIMATION}

In this section, the selection of the appropriate core is analyzed using the area product parameter. Based on this selection, different transformers are designed and compared in terms of size, losses, leakage inductance, series resistance and resonance frequency.

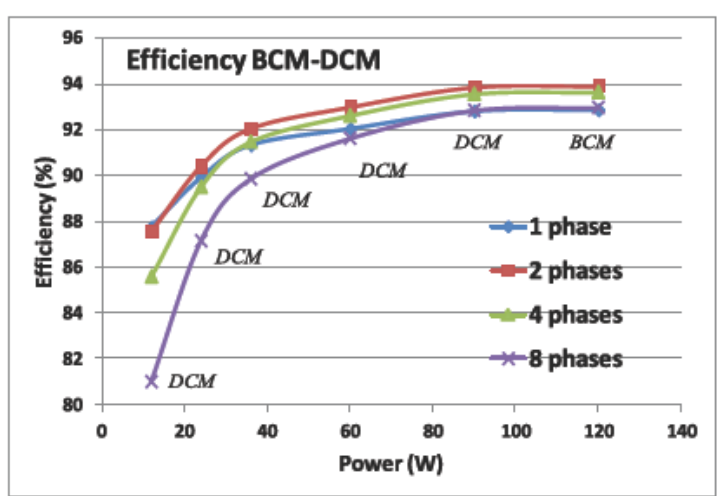

(a)

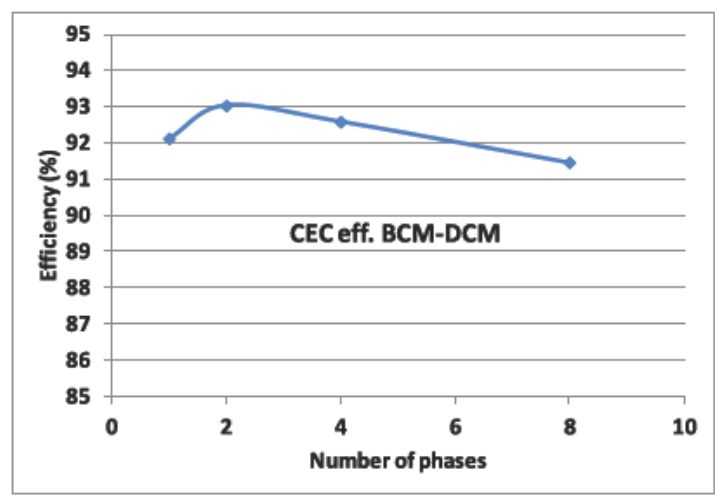

(b)

Fig. 10. Calculated efficiency for the analyzed configurations.

\section{A. Core Selection Based on Area Product Parameter}

The area product parameter $\left(A_{p}\right)$ is defined as the product of the cross section $\left(A_{e}\right)$ and the window area $\left(A_{w}\right)$ of a given core. This parameter can be used to estimate the volume and weight as well as the power-handling ability of a core [26] and it is easy to obtain from the core datasheets provided by the manufacturers. This parameter can be calculated according to (11), where "kw" is the window filling factor and " $\mathrm{B}_{\max }$ " and " $\mathrm{J}_{\max }$ " are the maximum allowed flux and current density, respectively. Only the primary and secondary windings currents are considered and an extra $20 \%$ is used to estimate the demagnetization windings

$$
A p=A e \cdot A w=\frac{V p \cdot d_{\max }}{B_{\max } \cdot f_{\min }} \cdot \frac{1.2 \cdot\left(I_{\mathrm{RMS}_{1}}+n \cdot I_{\left.\mathrm{RMS}_{2}\right)}\right.}{k_{w} \cdot J_{\max }} .
$$

Fig. 11 shows the estimated RM cores for the analyzed configurations of the proposed topology (one, two, four and eight transformers). The parameters used for the area product calculation and the primary to secondary transformer turns ratio for the different configurations are shown in Table I. In the presented designs, the reset turns ratio $(\mathrm{n} 3 / \mathrm{n} 1)$ is one and therefore the maximum applicable duty cycle is 0.5 . The primary to secondary turns ratio for each analyzed configuration is calculated according to the introduced PV module and grid voltages using (3) and imposing a maximum duty cycle of 0.45 . 


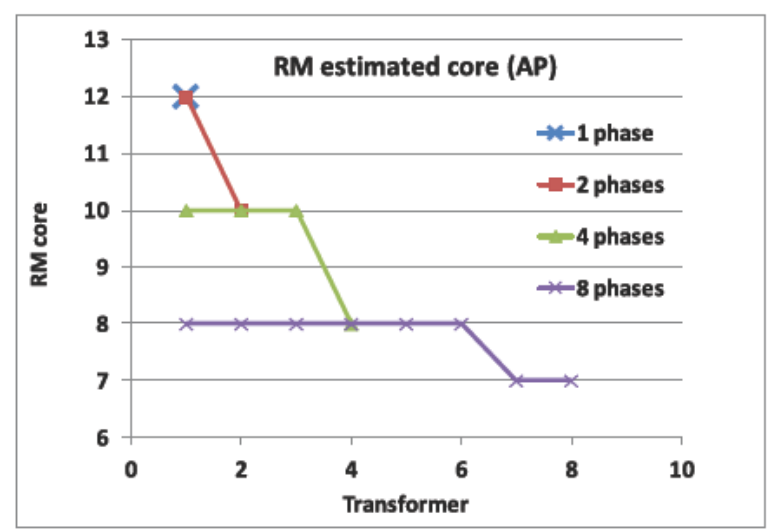

Fig. 11. Estimated RM cores based on the area product.

TABLE I

PARAMETERS AND TURNS RATIO USED IN THE RM CORE ESTIMATION

\begin{tabular}{lccc}
\hline \hline Parameter & Value & Phases & $\mathrm{n}(\mathrm{n} 2 / \mathrm{n} 1)$ \\
\hline Core/Material & $\mathrm{RM} / 3 \mathrm{C} 90$ & 1 & 8 \\
$\mathrm{kw}$ & 0.3 & & \\
$\mathrm{~J}_{\max }$ & $600 \mathrm{~A} / \mathrm{cm}^{2}$ & 2 & 4 \\
$\mathrm{~B}_{\max }$ & $0.65 \cdot \mathrm{Bsat}$ & & \\
$\mathrm{f}_{\min }$ & $70 \mathrm{kHz}$ & 4 & 2 \\
VPV & $45 \mathrm{~V}$ & & \\
$\mathrm{PPV}$ & $120 \mathrm{~W}$ & 8 & 1 \\
$\mathrm{~V}_{\mathrm{grid}}$ & $110 \mathrm{~V} @ 60 \mathrm{~Hz}$ & & \\
\hline \hline
\end{tabular}

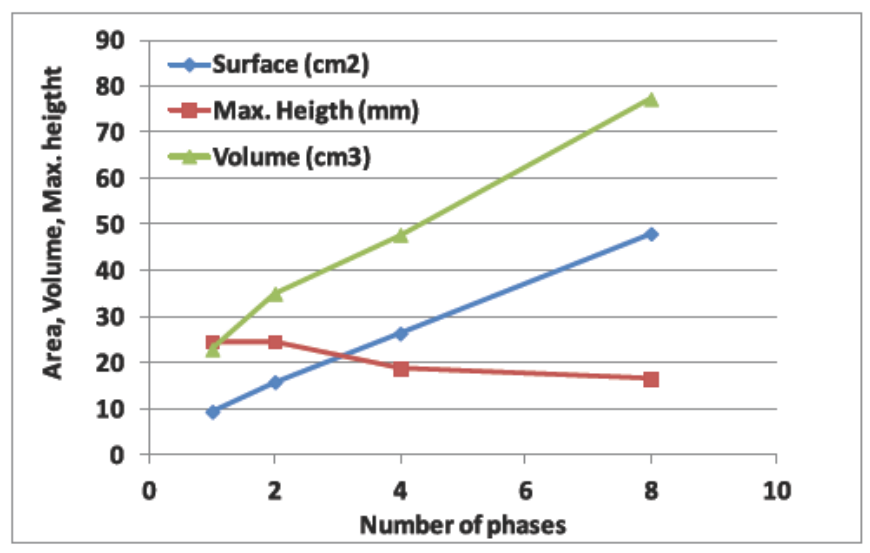

Fig. 12. Estimated volume (green), total area (blue) and height (red) of the selected transformers.

\section{B. Volume, Area and Height}

A design of each transformer for the different analyzed configurations has been developed based on the selected cores and the design parameters shown in Fig. 11 and Table 1. The maximum height as well as the total surface and volume of the designed transformers considering the bobbin are calculated for each configuration (see Fig. 12).

As shown in Fig. 12, the total estimated area occupied by the transformers increases with the number of phases as well as the total volume. However, the maximum estimated height decreases as the number of phases increase. It must be noticed that

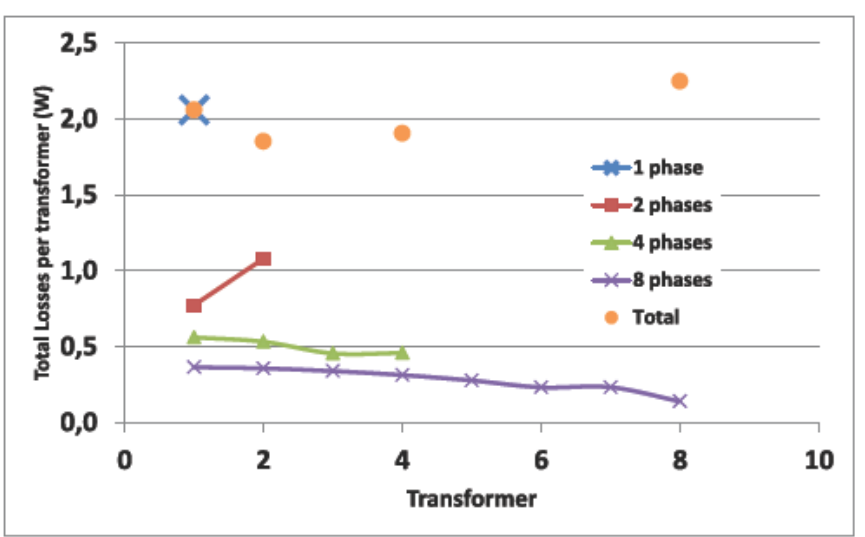

Fig. 13. Total losses in the transformers for the analyzed configurations.

in ac-module application the converter is attached to the back side of a PV module and, therefore, the available area is large. Furthermore, the low height allows mounting the microinverter in the frame of the solar module [27].

\section{Transformer Comparison}

Finite element analysis (FEA) has been used in order to compare the above presented designs in terms of losses, resonance frequency and leakage inductance. Fig. 13 shows the total calculated losses for each transformer and for the whole set of transformers for the analyzed configurations. The winding losses are calculated using the obtained FEA models. Regarding the core losses, the average over a line period is obtained based on the calculated losses at each switching cycle according to the Steinmetz equation.

As shown in Fig. 13 the difference in the calculated losses is not significant for the analyzed configurations. However, as the number of transformers increases the losses are more spread contributing to an easier thermal management.

Parasitic effects, such as the parasitic capacitance or leakage inductance, can deteriorate the performance of the converter. The parasitic capacitance of the primary winding has been estimated using FEA. This value is used together with the obtained magnetizing inductance to estimate the transformer resonance frequency. As show in Fig. 14, the resonance frequency of the analyzed solutions increases when the turn ratio gets closer to the unity, i.e., with the number of transformers. Another advantage of the proposed topology is that an increase in the number of transformers decreases significantly the leakage inductance and the series resistance of the designed transformers as shown in Figs. 15 and 16, hence improving the performance of the inverter.

\section{EXPERIMENTAL RESULTS}

A prototype of the single-transformer forward microinverter as well as prototypes of the two-transformer (best expected efficiency) and eight-transformer (lowest transformer height) of the proposed parallel-series microinverter have been designed and built to interface a $45 \mathrm{~V}, 120 \mathrm{~W}$ PV module to the US 


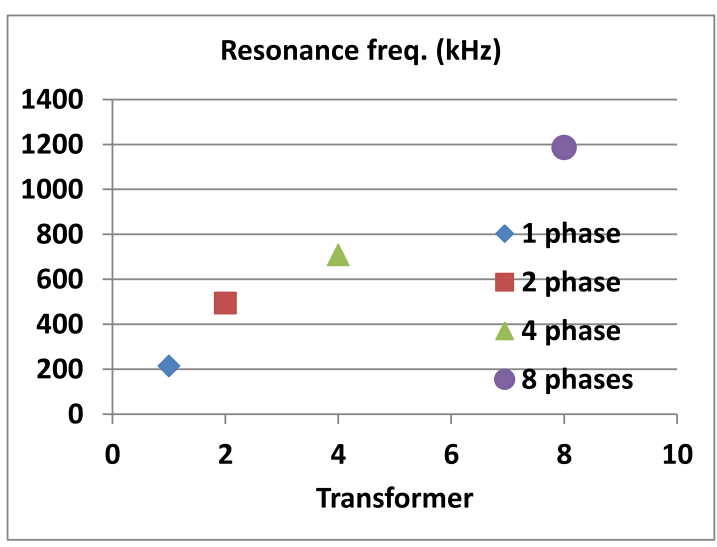

Fig. 14. Estimated resonant frequency of the analyzed designs.

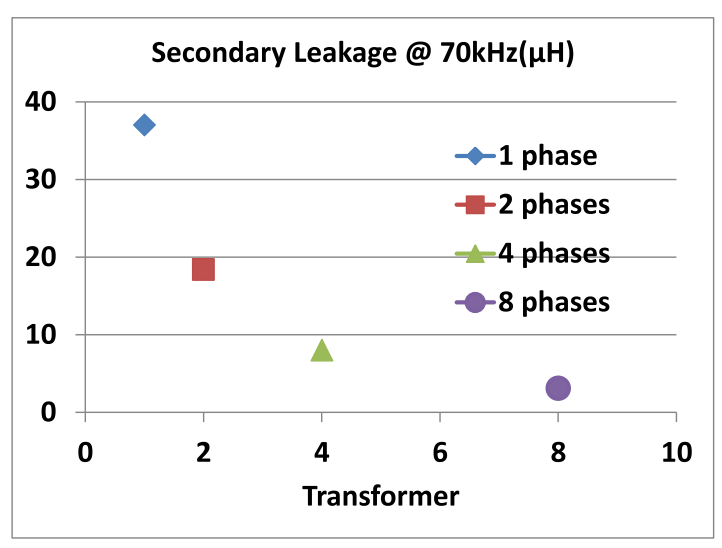

Fig. 15. Maximum secondary side leakage inductance of the analyzed designs.

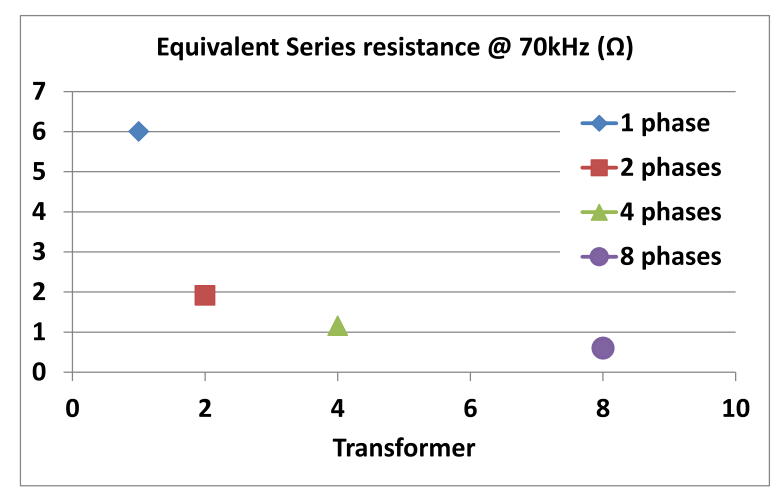

Fig. 16. Equivalent series resistance referred to secondary side of the analyzed designs.

grid (110 V@60 Hz). All the prototypes have the same output filter $(L=400 \mu \mathrm{H}$, ETD34-3F3 core; $C=1 \mu \mathrm{F})$, same primary switch (IRFS4410PbF) and same secondary side SiC diode (C3D02060E). The set of transformers of each prototype are designed according to the selected core for transformer 1 in Fig. 11: 1:8-RM12, 1:4-RM12 and 1:1-RM8, respectively. The control of the presented prototypes, for both modes of operation, is implemented in a TMS320F28069 microcontroller.

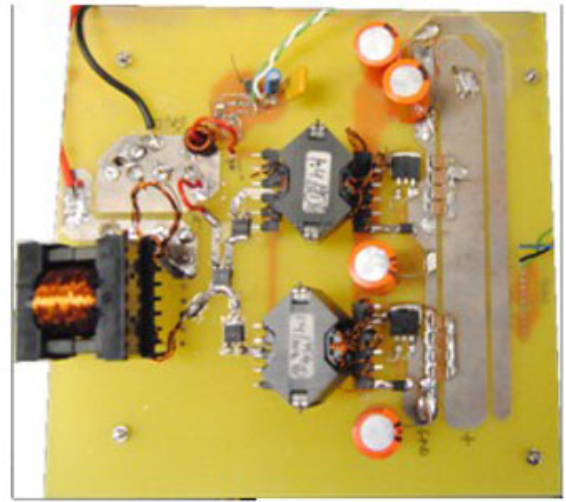

(a)

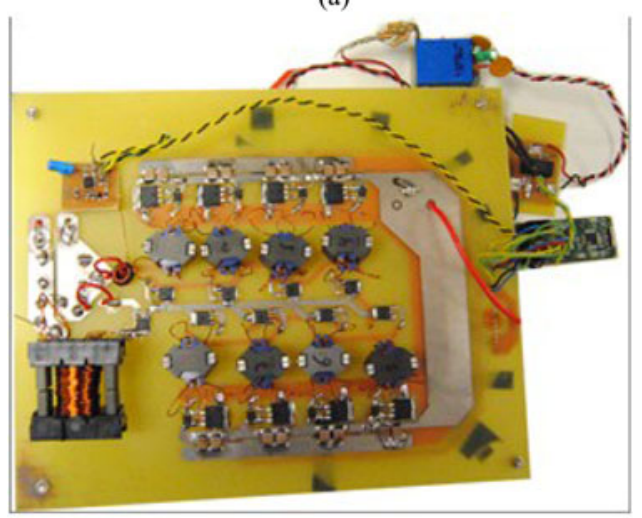

(b)

Fig. 17. (a) Two-transformer and (b) eight-transformer primary-parallel secondary-series forward microinverters.

Fig. 17(a) shows the two-transformer prototype with dimensions of $174 \times 193 \mathrm{~mm}$. The single transformer inverter was mounted using the same PCB. In the case of the eighttransformer prototype [see Fig. 17(b)], the dimensions are $254 \times$ $173 \mathrm{~mm}$. Despite the eight-transformer configuration has lower transformer profile, the maximum height is fixed by the $30 \mathrm{~mm}$ of the inductor ETD34 core. In terms of decoupling capacitor, the eight-transformer solution uses SMD ceramic capacitor while the one- and two-transformer circuits use both ceramic and electrolytic capacitors.

The presented results were obtained with a dc source in the input and the grid connection is emulated with an ac voltage source in parallel with a resistor. The dc input voltage was changed accordingly to the NA-F121 PV module voltages for a temperature of $50{ }^{\circ} \mathrm{C}$ for different irradiation (power) levels, emulating the MPPT behavior.

Fig. 18 shows the waveforms for BCM full-load (top) and DCM 20\%-load (bottom) operation for the single-transformer microinverter. In both cases, unity power factor current is injected into the grid. The inductor current substitutes the injected current in Fig. 19 to demonstrate the BCM operation at different grid voltages.

Fig. 20 shows the grid voltage (Ch1) and the injected current (Ch2), the unfolder driving signal (Ch4) and the voltage applied to the filter (Ch3) for the eight-transformer inverter at 


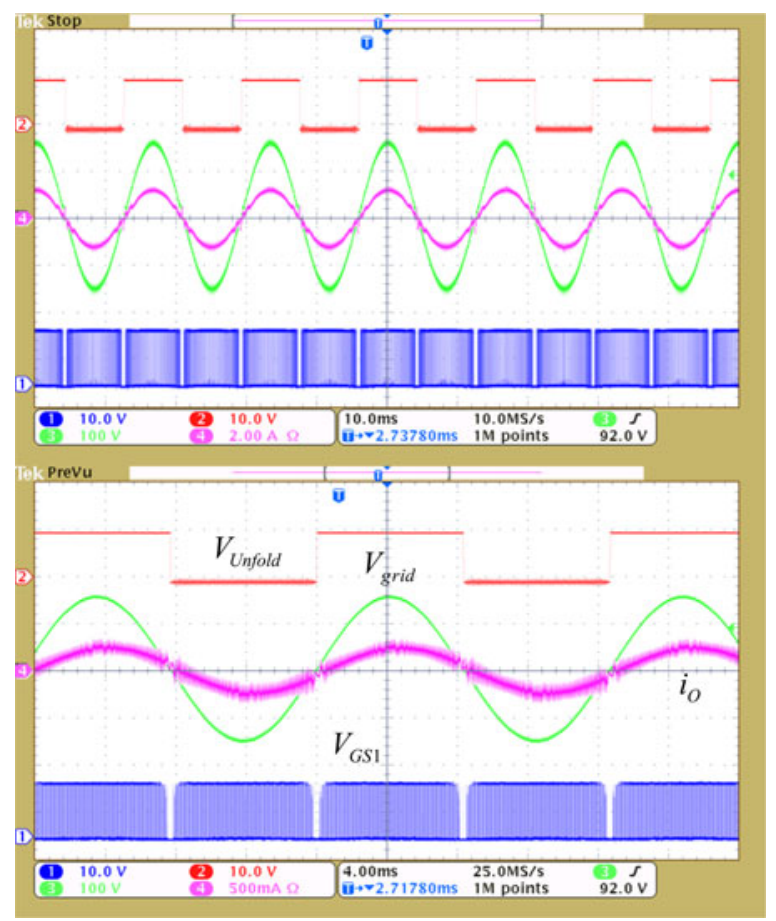

Fig. 18. Output voltage and current for the single transformer microinverter at BCM full-load (top) and DCM 20\% load (bottom) operation.

full-load BCM operation (top) and DCM operation at 30\% of the maximum power (bottom). As it can be seen from Fig. 20, the voltage applied to the filter increases with the number of phases depending on the grid voltage.

The same waveforms for the two-transformer prototype, except the gate to source voltage ( $\mathrm{Ch} 4)$ of the second phase switch (M2 in Fig. 5), are shown in Fig. 21. This phase is active when the grid voltage excesses half of the peak value.

The high-frequency waveforms of the tested configurations with multiple transformers are depicted in Fig. 22. The top side demonstrates the BCM operation of the eight-transformer microinverter when switch 4 is turned OFF. Bottom waveforms in Fig. 22 present the moment when switch 2 turns OFF in the two-transformer prototype at DCM operation.

The efficiency and THD results obtained are presented in Figs. 23 and 24, respectively, for the three introduced prototypes. In terms of THD, the eight-phases transformer configuration presents a better performance in the whole power range, being under the 5\%. In terms of efficiency (including the driving stage), the prototype with the highest turns ratio (1:8) presents the lowest efficiency in the whole power range, and lower than the estimated one. In the case of the multicore configurations, the eight-transformer one (with 1:1 transformers) performs better in the full-load range while the two-transformer solution is better in the light-load power levels. As a result, the prototypes with multiple transformers have a CEC efficiency of $92.4 \%$ while the single-transformer microinverter-weighted efficiency is $90.1 \%$.

Figs. 25 and 26 show the thermal response of the prototypes with multiple transformers at full load, being better the thermal management of the eight-transformer prototype. The maximum

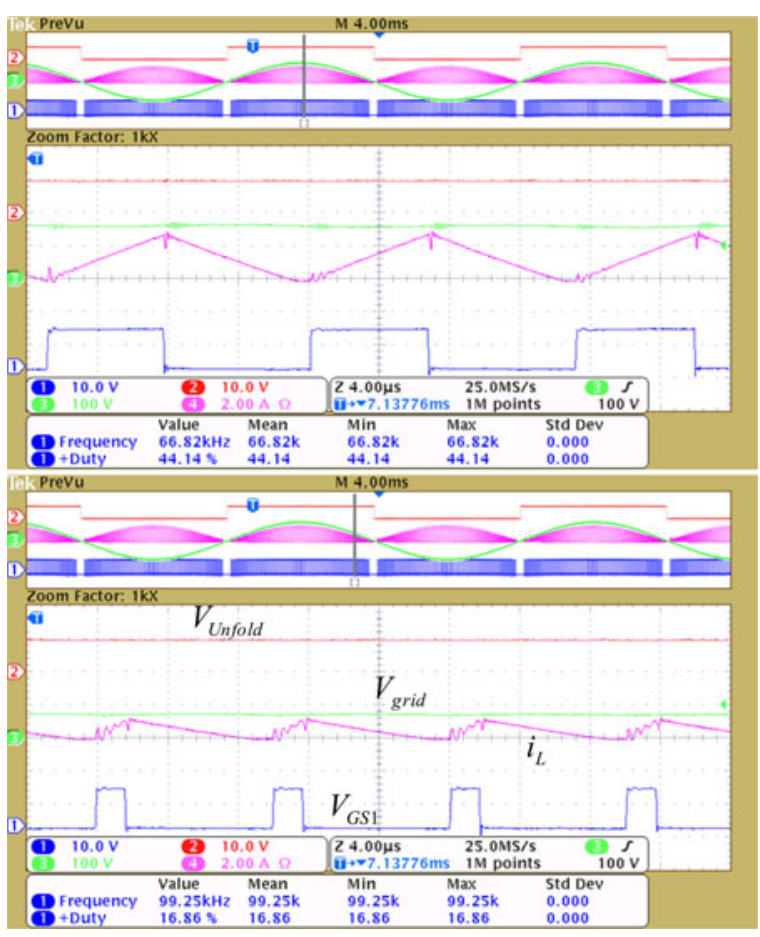

Fig. 19. Inductor current and primary switch driving signal of the onetransformer inverter for BCM operation at different grid voltages.

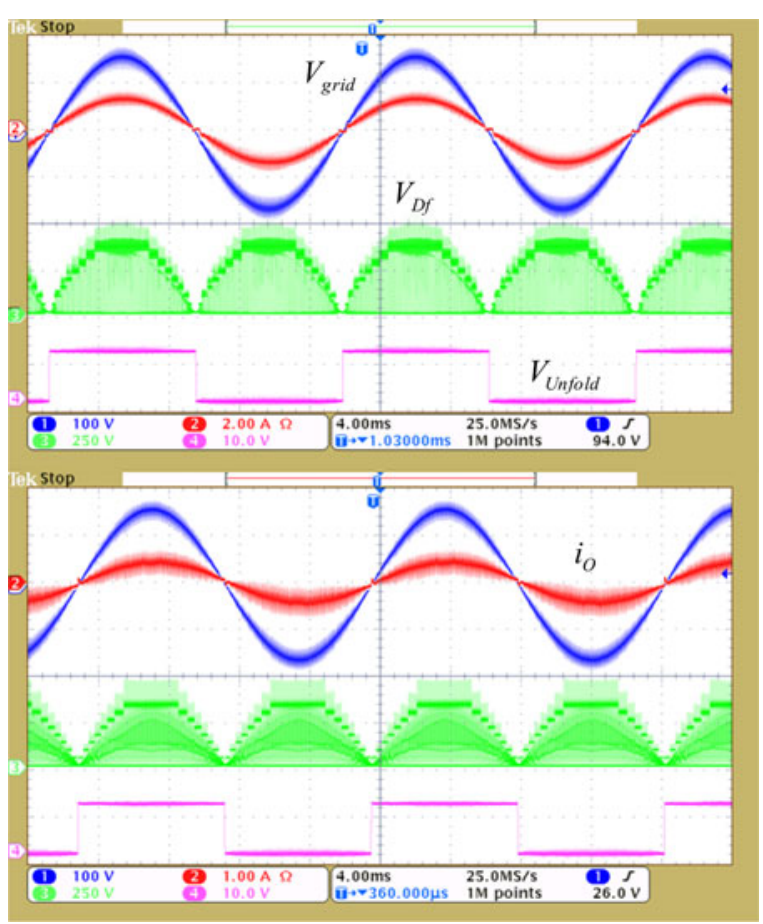

Fig. 20. Output voltage and current and free-wheeling diode voltage for the eight-transformer microinverter at BCM full-load (top) and DCM 30\% load (bottom) operation. 


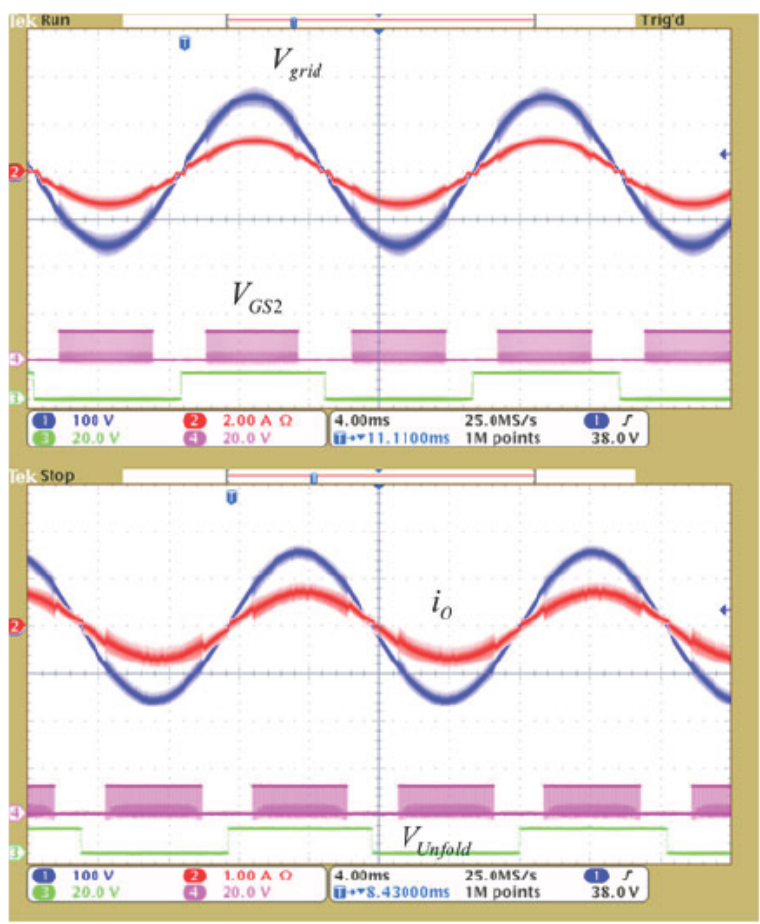

Fig. 21. Output voltage and current and M2 driving signal for the twotransformer microinverter at BCM full-load (top) and DCM 50\% load (bottom) operation.

temperature is located at the freewheeling diode for both prototypes, being over $70^{\circ} \mathrm{C}$. In the case of the primary switches the maximum temperatures are $60^{\circ} \mathrm{C}$ and $40^{\circ} \mathrm{C}$ for the two- and the eight-transformer configurations, corresponding with the MOSFET in transformer 1 (M1 in Fig. 5) which is the switch that is continuously $\mathrm{ON}$.

\section{A. Comparison With the Multiphase-Interleaved Forward Microinverter}

A low profile prototype of an eight-transformer-interleaved forward microinverter (see Fig. 27) has been built to compare with the proposed parallel-series microinverter, under the same specifications and using the same semiconductors. The set of transformers of the interleaved prototype consists of eight 1:8RM8 transformers. The output filter $(\mathrm{L}=3.2 \mathrm{mH} ; C=122 \mathrm{nF})$ inductors are designed with RM7 cores. The decoupling capacitor, which is the same than for the previously presented prototypes is implemented with SMD ceramic capacitors and the total area of the prototype is $298 \times 199 \mathrm{~mm}$, with a maximum height of $16.5 \mathrm{~mm}$.

The injected current and the inductor current of two phases at full-load operation are shown in Fig. 28. Detailed inductor current waveforms are shown in Fig. 29 for full-load and halfload operation. As it can be seen, the phase delay of the phases changes according to the number of active phases to keep the interleaved operation.

As for the proposed parallel-series inverter, the efficiency of the interleaved microinverter has been measured at different power levels in order to compute the CEC efficiency (Fig. 30).

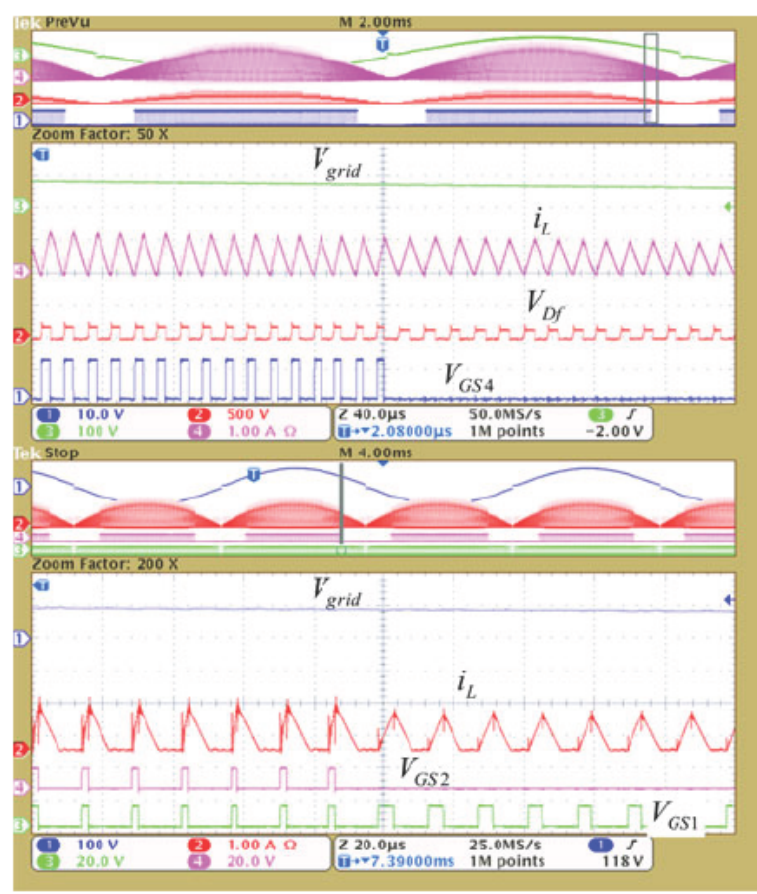

Fig. 22. Inductor current, free-wheeling diode voltage and driving signals of the BCM eight-transformer (top) and DCM two-transformer (bottom) operation

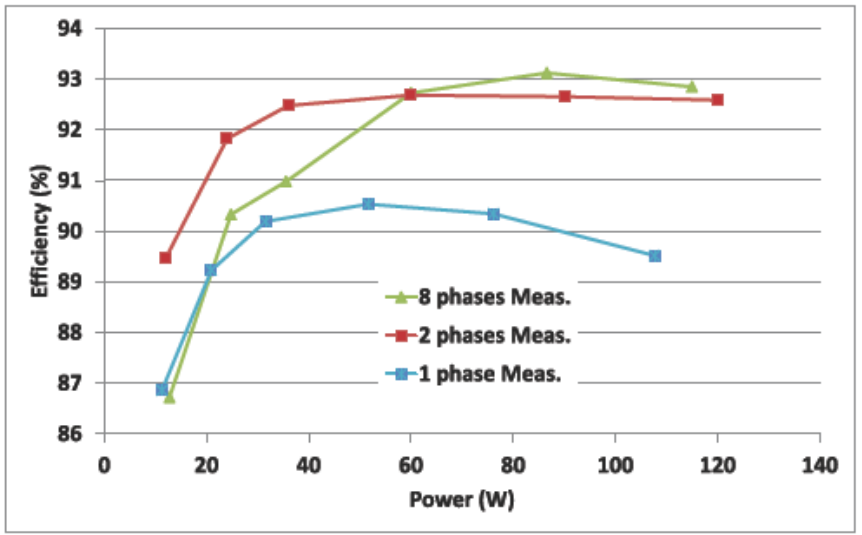

Fig. 23. Measured efficiency for the proposed configurations.

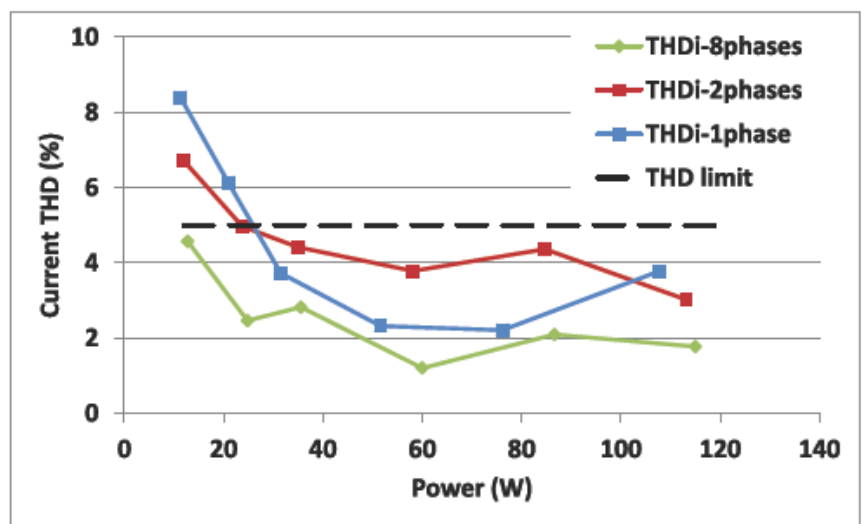

Fig. 24. Current THD measured for the three tested microinverters. 


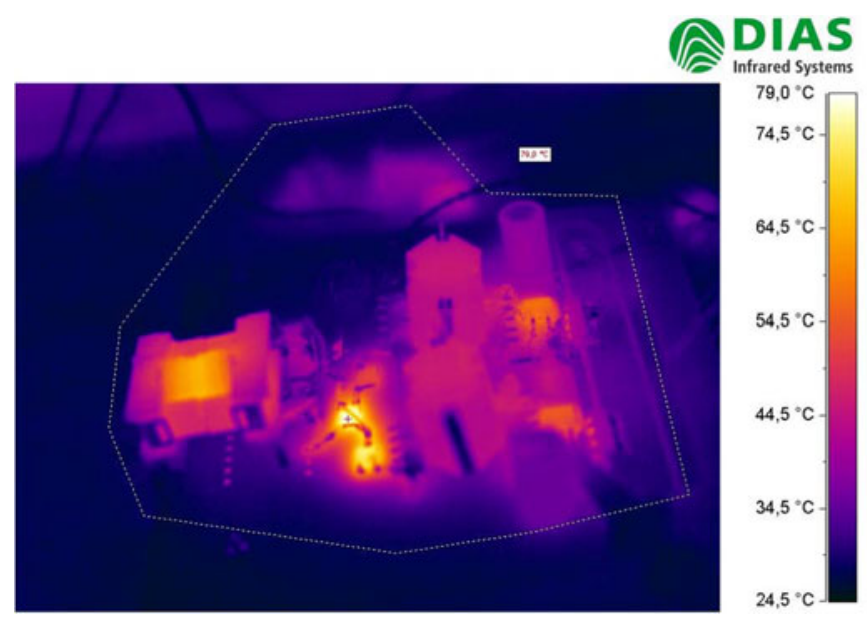

Fig. 25. Thermal image of the two-transformer prototype.

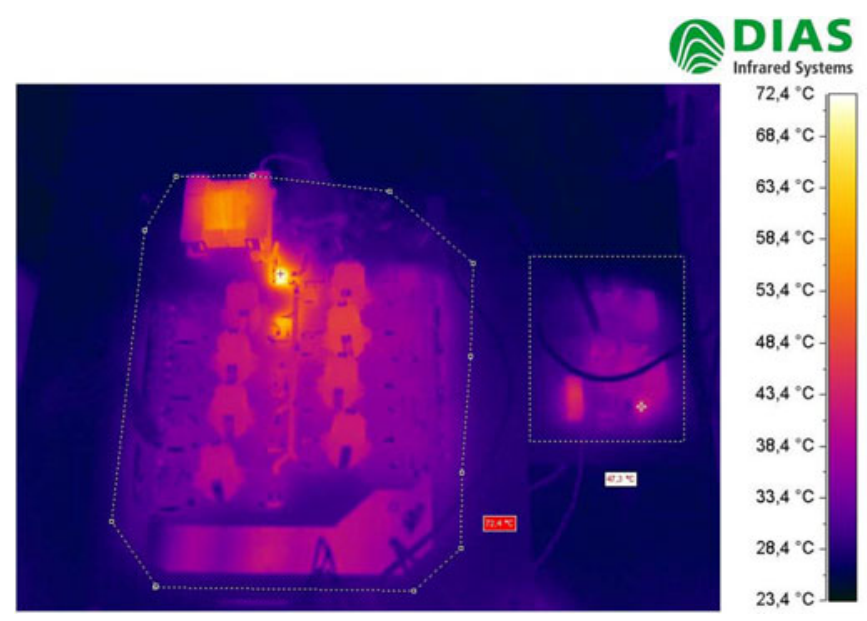

Fig. 26. Thermal image of the eight-transformer prototype.

As expected, the interleaved solution improves the light-load efficiency, which slightly increases the CEC efficiency from $90.1 \%$ of the single-transformer inverter to $90.9 \%$. However, the parallel-series converter performance is better for the most of the operation power range and therefore presents a higher CEC efficiency as mentioned previously.

\section{B. Qualitative Cost Comparison}

In this section, a qualitative cost comparison between the two eight-transformer configurations is presented, considering the single-transformer inverter as a reference.

The number of primary switches in both multiphase configurations is the same, which is eight times higher than in the single-transformer. However, the current stress is drastically reduced, even more in the case of the parallel-series configuration where 1:1 transformers are used. Therefore, higher on resistance devices could be used and a factor of 5 is estimated for the switches cost increase. Regarding the secondary side diodes, the parallel-series configuration presents an increase from two to nine diodes, with different current and voltage stresses, while

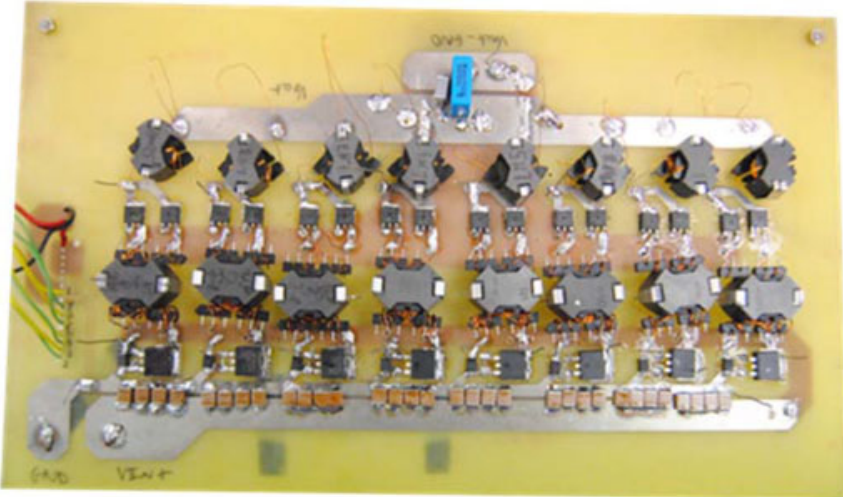

Fig. 27. Eight-phases forward-interleaved prototype.

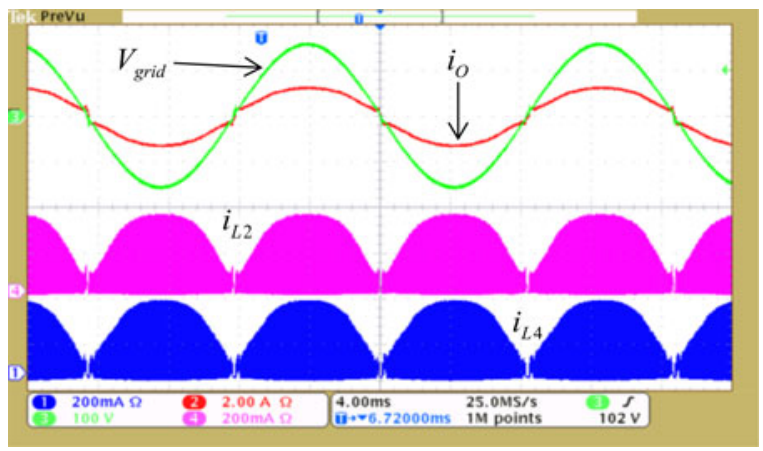

Fig. 28. Output voltage and current and phase inductor currents for the eightphase-interleaved prototype at full-load.

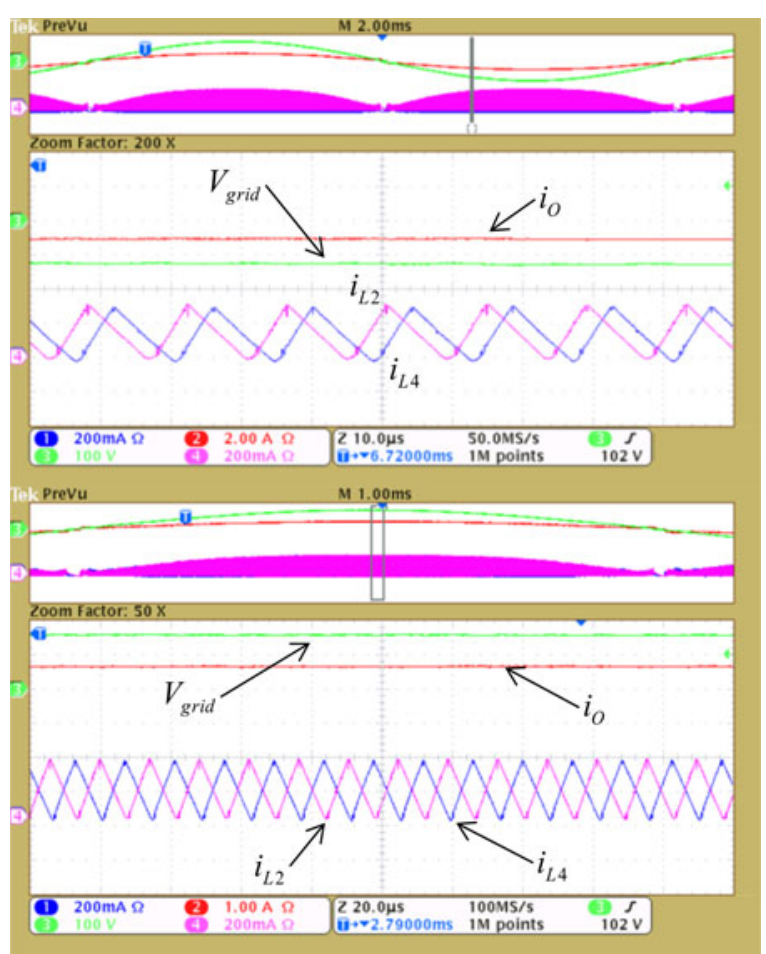

Fig. 29. $120 \mathrm{~W}$ (eight phases) and $60 \mathrm{~W}$ (four phases) inductor currents for the eight-phase-interleaved forward microinverter. 


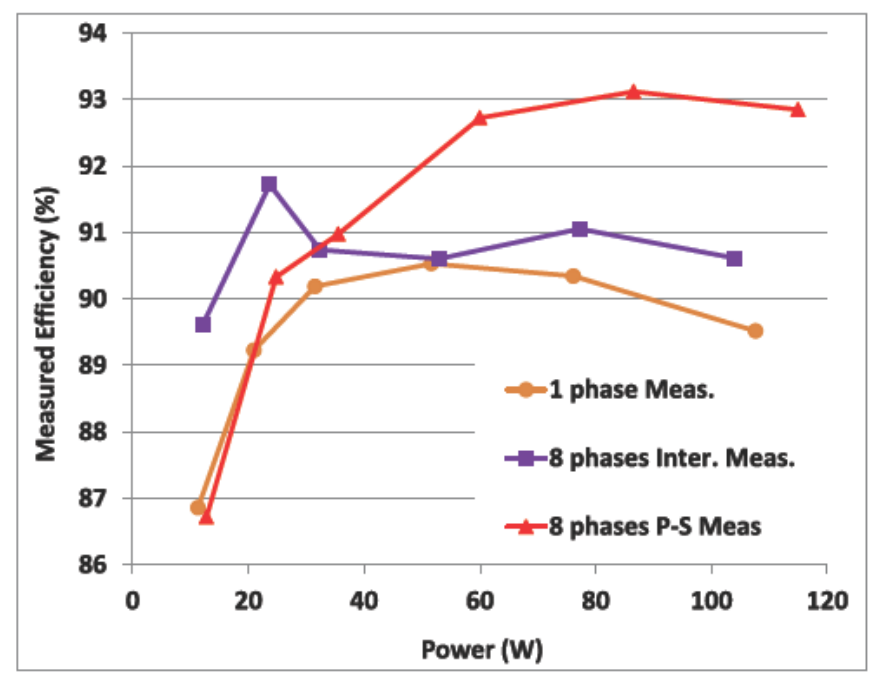

Fig. 30. Measured efficiency of the interleaved prototype compared with the parallel-series-measured efficiency.

the interleaved solution has eight times more devices than the reference design but with a drastic reduction in the current stress. As a consequence, a factor of 4 can be considered for the diode cost increase of both multiphase inverters.

In terms of magnetic components, the interleaved inverter needs more inductors for the output filter thus increasing the cost in respect to the parallel-series or the reference inverters, since they have the same output inductor. Taking into consideration the transformer set, a cost reduction of around $20 \%$ is estimated in the parallel-series configuration due to the utilization of standardized 1:1 transformers over the customized design of the 1:8 single-transformer. The interleaved solution is more expensive in this sense since eight customized transformers are needed.

\section{CONCLUSION}

This paper introduces a multiphase primary-parallel secondary-series forward microinverter operated in boundary and DCM, suitable for PV ac-module application. The key parameter is the number of transformers and its influence in terms of size, losses, leakage inductance, series resistance and resonance frequency of the transformers is explored. An increase in the number of transformers allows the utilization of better coupled transformers, improving the inverter performance. The total surface of the proposed solution increases with the number of transformers, however the height decreases making the solution suitable for PV ac-module application. DCM operation is introduced to overcome the performance degradation due to the increase in the operation frequency of BCM at light load. Based on the analysis, single transformer prototype as well as prototypes of 2 and 8 transformers were built. Both multitransformer inverters present the same weighted efficiency of $92.4 \%$, improving the single-transformer inverter performance in around $2 \%$. Despite in the proposed designs the inductor limits the height of both solutions, the low-profiled eight-transformer con- figuration allows using ceramic capacitors and offers better THD and thermal management capabilities, reducing the primary side temperature in $20^{\circ} \mathrm{C}$. The proposed parallel-series microinverter is compared to a classical eight-transformer-interleaved forward microinverter. The light-load efficiency is improved in the interleaved approach, but the single-transformer efficiency is slightly improved (less than $1 \%$ ) and the CEC efficiency is lower than the parallel-series approach. The parallel-interleaved implementation presents a height reduction of $45 \%$ in respect to the parallel-series prototype, with an increase of $20 \%$ in area.

\section{REFERENCES}

[1] N. Femia, G. Lisi, G. Petrone, G. Spagnuolo, and M. Vitelli, "Distributed maximum power point tracking of photovoltaic arrays: Novel approach and system analysis," IEEE Trans. Ind. Electron., vol. 55, no. 7, pp. 2610-2621, Jul. 2008.

[2] L. Quan and P. Wolfs, "A review of the single phase photovoltaic module integrated converter topologies with three different DC link configurations," IEEE Trans. Power Electron., vol. 23, no. 3, pp. 1320-1333, May 2008.

[3] L. Wuhua and H. Xiangning, "Review of nonisolated high-step-up DC/DC converters in photovoltaic grid-connected applications," IEEE Trans. Ind. Electron., vol. 58, no. 4, pp. 1239-1250, Apr. 2011.

[4] D. Meneses, F. Blaabjerg, O. Garca, and J. A. Cobos, "Review and comparison of step-up transformerless topologies for photovoltaic AC-module application," IEEE Trans. Power Electron., vol. 28, no. 6, pp. 2649-2663, Jun. 2013.

[5] Z. Yi, L. Wuhua, D. Yan, and H. Xiangning, "Analysis, design, and experimentation of an isolated ZVT boost converter with coupled inductors," IEEE Trans. Power Electron., vol. 26, no. 2, pp. 541-550, Feb. 2011.

[6] B. York, Y. Wensong, and L. Jih-Sheng, "An integrated boost resonant converter for photovoltaic applications," IEEE Trans. Power Electron. vol. 28, no. 3, pp. 1199-1207, Mar. 2013.

[7] C. Dong, J. Shuai, F. Z. Peng, and L. Yuan, "Low cost transformer isolated boost half-bridge micro-inverter for single-phase grid-connected photovoltaic system," in Proc. 27th Annu. IEEE Appl. Power Electron. Conf. Expo., Feb. 2012, pp. 71-78.

[8] C. Huang-Jen, L. Yu-Kang, Y. Chun-Yu, C. Shih-Jen, H. Chi-Ming, C. Ching-Chun, K. Min-Chien, H. Yi-Ming, J. Yuan-Bor, and H. YungCheng, "A module-integrated isolated solar microinverter," IEEE Trans. Ind. Electron., vol. 60, no. 2, pp. 781-788, Feb. 2013.

[9] A. Fernandez, J. Sebastian, M. M. Hernando, M. Arias, and G. Perez, "Single stage inverter for a direct AC connection of a photovoltaic cell module," in Proc. 37th IEEE Power Electron. Spec. Conf., Jun. 2006, pp. 1-6.

[10] Z. Zhiliang, H. Xiao-Fei, and L. Yan-Fei, "An optimal control method for photovoltaic grid-tied-interleaved flyback microinverters to achieve high efficiency in wide load range," IEEE Trans. Power Electron., vol. 28, no. 11 , pp. 5074-5087, Nov. 2013

[11] H. D. Thai, J. Barbaroux, H. Chazal, Y. Lembeye, J. C. Crebier, and G. Gruffat, "Implementation and analysis of large winding ratio transformers," in Proc. 24th Annu. IEEE Appl. Power Electron. Conf. Expo., Feb. 2009, pp. 1039-1045.

[12] C. Daolian and L. Lei, "Novel static inverters with high frequency pulse DC link," IEEE Trans. Power Electron., vol. 19, no. 4, pp. 971-978, Jul. 2004.

[13] A. Costabeber, P. Mattavelli, and S. Saggini, "Digital time-optimal phase shedding in multiphase buck converters," IEEE Trans. Power Electron., vol. 25 , no. 9 , pp. 2242-2247, Sep. 2010.

[14] M. Fornage, "Method and apparatus for converting direct current to alternating current," U.S. Patent US 7796412 B2, Sep. 14, 2010.

[15] O. Ziwei, G. Sen, O. C. Thomsen, and M. A. E. Andersen, "Analysis and design of fully integrated planar magnetics for primary-parallel isolated boost converter," IEEE Trans. Ind. Electron., vol. 60, no. 2, pp. 494-508, Feb. 2013.

[16] S. K. Mazumder, T. Sarkar, and K. Acharya, "A direct FET based highfrequency fuel-cell inverter," in Proc. 24th Annu. IEEE Appl. Power Electron. Conf. Expo., Feb. 2009, pp. 1805-1812.

[17] M. T. Zhang, M. M. Jovanovic, and F. C. Y. Lee, "Analysis and evaluation of interleaving techniques in forward converters," IEEE Trans. Power Electron., vol. 13, no. 4, pp. 690-698, Jul. 1998. 
[18] P. Ki-Bum, M. Gun-Woo, and Y. Myung-Joong, "Series-input seriesrectifier interleaved forward converter with a common transformer reset circuit for high-input-voltage applications," IEEE Trans. Power Electron., vol. 26, no. 11, pp. 3242-3253, Nov. 2011.

[19] Z. Guoxing, W. Xinke, Y. Wei, Z. Junming, and Q. Zhaoming, “A new interleaved active-clamp forward converter with parallel input and seriesparallel output," in Proc. 24th Annu. IEEE Appl. Power Electron. Conf. Expo., Feb. 2009, pp. 40-44.

[20] A. Fernández, J. Sebastian, M. M. Hernando, M. Arias, and G. Perez, "Single stage inverter for a direct AC connection of a photovoltaic cell module," in Proc. Power Electron. Spec. Conf., Jun. 2006, pp. 1-6.

[21] H. Haibing, S. Harb, N. Kutkut, I. Batarseh, and Z. J. Shen, "Power decoupling techniques for micro-inverters in PV systems: A review," in Proc. IEEE Energy Convers. Congr. Expo., Sep. 2010, pp. 3235-3240.

[22] S. V. Araujo, P. Zacharias, and R. Mallwitz, "Highly efficient single-phase transformerless inverters for grid-connected photovoltaic systems," IEEE Trans. Ind. Electron., vol. 57, no. 9, pp. 3118-3128, Sep. 2010.

[23] Generators Connected to the Low-Voltage Distribution NetworkTechnical Requirements for the Connection to and Parallel Operation With Low-Voltage Distribution Networks, VDE Standard VDE-AR-N 4105, 2011.

[24] Y. Fei, R. Xinbo, J. Qing, and Y. Zhihong, "Input differential-mode EMI of CRM boost PFC converter," IEEE Trans. Power Electron., vol. 28, no. 3, pp. 1177-1188, Mar. 2013.

[25] S. B. Kjaer, J. K. Pedersen, and F. Blaabjerg, "A review of singlephase grid-connected inverters for photovoltaic modules,” IEEE Trans. Ind. Appl., vol. 41, no. 5, pp. 1292-1306, Sep./Oct. 2005.

[26] W.-J. Gu and R. Liu, "A study of volume and weight versus frequency for high-frequency transformers," in Proc. 24th Annu. IEEE Power Electron. Spec. Conf., Jun. 1993, pp. 1123-1129.

[27] M. Meinhardt, T. O’Donnell, H. Schneider, J. Flannery, C. O. Mathuna, P. Zacharias, and T. Krieger, "Miniaturized "low profile" module integrated converter for photovoltaic applications with integrated magnetic components," in Proc. 14th Annu. Appl. Power Electron. Conf. Expo., Mar. 1999, pp. 305-311.

[28] W. Bower, et al.: Performance test protocol for evaluating inverters used in grid-connected photovoltaic systems, Inst. Sustainable Technol., 2004. 